\title{
THE EFFECT OF PRETREATMENT WITH TOLL-LIKE RECEPTOR 4 ANTAGONIST RESATORVID ON METHOTREXATE-INDUCED LIVER INJURY IN RATS: HISTOPATHOLOGICAL STUDY
}

\author{
BASSIM I MOHAMMAD ${ }^{1}$, BASSIM S AHMED ${ }^{2}$, ALAA F HASSAN ${ }^{3 *}$, SAMER F HASSAN ${ }^{4}$ \\ ${ }^{1}$ Depatment of Pharmacology, College of Pharmacy, University of Al-Qadisiyah, Qadisiyah, Iraq. ${ }^{2}$ Depatment of Pathology and Forensic \\ Medicine, College of Medicine, Mustansiriyah University, Baghdad, Iraq. ${ }^{3}$ Depatment of Pharmacy, Al-Mahmoudiya General Hospital, \\ Baghdad, Iraq. ${ }^{4}$ Depatment of Surgery, College of Medicine, Wasit University, Wasit, Iraq. E-mail: alaa.alwazni@yahoo.co.uk
}

Received: 29 September 2018, Revised and Accepted: 03 November 2018

ABSTRACT

Objective: This research aims to evaluate the histopathological changes after pretreatment with resatorvid against methotrexate induced-liver injury.

Methods: 28 male albino-wistar rats divided into random 4 groups (7 rats in each). Control group: Rats left untreated. Vehicle pre-treated group: Rats were administered dimethyl sulfoxide (DMSO) followed by methotrexate (MTX). Methotrexate treated group: Rats left untreated then administered MTX. Resatorvid pre-treated group: Rats were administered resatorvid followed by MTX. $24 \mathrm{~h}$ after the end of treatment, the animals were sacrificed. Liver tissue samples dissected out immediately and fixed in 10\% formalin. The traditional procedures (paraffin-embedded method) was used to prepare liver tissue for microscopic evaluation by none alcoholic fatty liver disease (NAFLD) Activity Score Components.

Results: Liver tissue sections of MTX-treated group show moderate-to-severe steatosis of hepatic cells and micro- and macro- hepatocellular fatty degeneration and giant fatty cysts with chronic inflammatory cells infiltration. While liver tissue sections of the resatorvid pre-treated group show moderate hepatic cellular fatty degeneration, with a decreased number of fatty cysts chains and the inflammation disappeared.

Conclusion: Resatorvid hepatoprotective effect against MTX-induced injury was promising throughout resolving the accompanying inflammation and partial restoring histopathological fatty alterations.

Keywords: Liver steatosis, Methotrexate sodium, Resatorvid, TLR4 receptor

(C) 2018 The Authors. Published by Innovare Academic Sciences Pvt Ltd. This is an open access article under the CC BY license (http://creativecommons. org/licenses/by/4. 0/) DOI: http://dx.doi.org/10.22159/ajpcr.2018.v11i12.29939

\section{INTRODUCTION}

Resatorvid is a selective inhibitor of toll-like receptor 4 (TLR4) signal transduction pathway. It interferes with the intracellular toll/ interleukin-receptor (TIR) domain adaptor molecule interaction [1,2]. Its structure (Fig. 1) with $\alpha-\beta$ unsaturated carbonyl group would allow it to act as Michael acceptor, via its cyclohexene ring which covalently bonds the nucleophilic cysteine 747 residue (Cys747) located at TIR domain that is necessary for TLR4 homodimeraization phase $[3,4,5]$.

TLR4 is a member of the pattern recognition receptor (PRR), the family that are widely expressed by hepatic, parenchymal and/nonparenchymal cells as well as activate hepatic tissue inflammatory response [6,7]. Hepatocytes are the main site for PRR expression despite their weak response to TLR4 ligand. Hepatic kupffer cells (KCs), stellate cells (HSCs), and dendritic cells directly respond to TLR after their activation producing pro-inflammatory cytokines (CKs) that are the end product of TLRs pathways while playing an indefinite role in sinusoidal endothelial cells (SECs). TLRs are also expressed by lymphocytes [6-8]. Therefore, TLR4 is perhaps an attractive target for MTX-induced liver injury since MTX hepatotoxicity involves generation of free radicals (FR), oxidative stress and imbalance of cellular oxidant/antioxidant enzymes, these mechanisms lead to immune stimulation and production of proinflammatory CKs that may involve TLR4 induced inflammatory pathways [9-12].

\section{Aim of the study}

This research aims to evaluate the histopathological changes after pretreatment with resatorvid against methotrexate induced-liver injury in an albino-wistar rat model.

\section{METHODS}

\section{Experimental design}

A total of 28 male albino Wistar rats (aged 4-6 mo and weighed 125-225 g) taken from Kut Technical Institute, University of Wasit, were maintained under non-specific pathogen-free conditions in wiremeshed cages ( 7 rats in each cage) with ad libitum access to water and regular diet. The animals were kept under a constant temperature $24 \pm$ $3^{\circ} \mathrm{C}$ with $12: 12 \mathrm{~h} \mathrm{light}$ dark cycle [13-15]. Animal handling and housing have proceeded in accordance with the international guidelines for the care and use of laboratory animals of the National Research Council $[13,14]$. The ethical committee of the Pharmacology Department, College of Medicine, Mustansiriyah University, approved the experiment.

The animals were divided into random four groups $(7$ rats in each group) $[14,16]$ : Control group: Rats kept on a regular diet and distilled water $(\mathrm{D} / \mathrm{W})$ throughout the 14 experimental $\mathrm{d}$. Vehicle pre-treated group: Rats were administered intraperitoneal (i.p.) DMSO once for $7 \mathrm{~d}[16,17]$, followed by $7 \mathrm{~d}$ of oral MTX $0.2 \mathrm{mg} / \mathrm{kg} / \mathrm{d}$ once via rat oral gavage [14]. Methotrexate treated group: Rats were left untreated for $7 \mathrm{~d}$ followed by $7 \mathrm{~d}$ of oral MTX $0.2 \mathrm{mg} / \mathrm{kg} / \mathrm{d}$ once dependent on the adult dose for rheumatoid arthritis to stimulate model of induced liver injury [14]. Resatorvid pre-treated group: Animals were administered i.p. resatorvid $5 \mathrm{mg} / \mathrm{kg} / \mathrm{d}$ once for $7 \mathrm{~d}$ [16], followed by $7 \mathrm{~d}$ of oral MTX $0.2 \mathrm{mg} / \mathrm{kg} / \mathrm{d}$ via rat oral gavage [14].

Chemical and drug preparation

Resatorvid $\left(\mathrm{C}_{15} \mathrm{H}_{17} \mathrm{CIFNO}_{4} \mathrm{~S}\right.$ - a white crystalline powder with DMSO solubility of $\geq 360 \mathrm{mg} / \mathrm{mL}$ according to the manufacturer) was purchased from MedChemExpress, New Jersey, USA. It was dissolved in 
DMSO and diluted with D/W to a final concentration of $17 \mathrm{mg} / \mathrm{ml} 1 \mathrm{~h}$. Before it was administered i.p. according to rat's weight [16,17]. MTX $\left(\mathrm{C}_{20} \mathrm{H}_{22} \mathrm{~N}_{8} \mathrm{O}_{5}-50 \mathrm{mg} / \mathrm{ml}\right.$ injectable solution) was purchased from KOÇAK Farma, ÍSTANBUL, Turkey, diluted with D/W to a final concentration of $0.333 \mathrm{mg} / \mathrm{ml}$ and administered via rat oral gavage according to rat weight [14]. DMSO: It was purchased as 99.5\% solution from Central Drug House (P) Ltd., New Delhi, India. It was diluted with D/W to $8 \% \mathrm{w} / \mathrm{v}$ solution (the concentration used to dissolve resatorvid) and administered i.p. according to resatorvid protocol and rats weight $[16,17]$.

\section{Tissue sample collection and histopathological study}

After $24 \mathrm{~h}$ of the end of the treatment, the rats were anaesthetized with Ketamine $91 \mathrm{mg} / \mathrm{kg}$-Xylazine $9 \mathrm{mg} / \mathrm{kg}$ intramuscularly (I.M.), both were achieved from Alfasan woerden, Woerden, and Kepro, Deventer, Holland respectively $[18,19]$. A cut was done to rats' abdomen using sharp scissor after animal scarification, and the liver was dissected out immediately. Liver tissue samples were fixed in containers with $30 \mathrm{ml}$ of $10 \%$ formalin and stored in $-28^{\circ} \mathrm{C}$ until their processing $[16,20,21]$.

The traditional processing procedures of the paraffin-embedded method were used to prepare liver tissues for microscopic evaluation [22-24]. The procedures include liver tissues' fixation in formalin $10 \%$, crosssectional slicing, and tissue step-by-step dehydration in graduated ethanol series clearing the dehydrant using xylene $[25,26]$. Infiltration followed, tissue blocks embedding in paraffin and being placed in metal mold, labeled, discarding any paraffin excess, and allowing the paraffin to congeal at room temperature then placed in refrigerator. Steps continued with infiltration, tissue blocks embedding in paraffin and then placing them in a metal mould, labelling was done, followed by discarding paraffin excess, and allowing the paraffin to congeal at room temperature then transfer them to refrigerator [26]. Manual tissue sectioning utilizing microtome was done, followed by marking the cleansed slides with a diamond pen and adjustment of obtained tissue sections on slide surfaces by utilizing water bath at $45^{\circ} \mathrm{C}$. Pulling

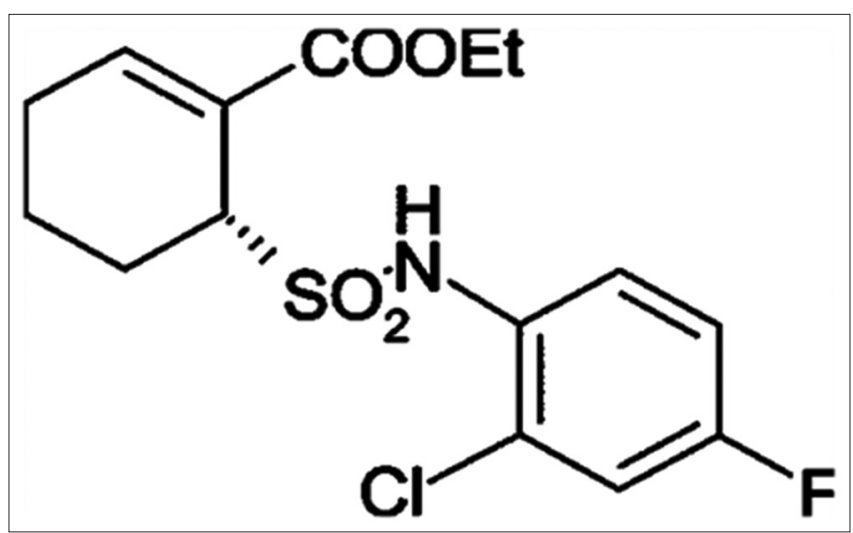

Fig. 1: Chemical structure of resatorvid [3] the slides out to allow tissue section adherence to the slide surfaces. Drying the obtained slides in a storage box for $24 \mathrm{~h}$. Tissue sections clearing and rehydration by xylene solution, alcohol and water performed for several times. Moving the slide box's into a hot oven with $65^{\circ} \mathrm{C}$ for $15 \mathrm{~min}$ followed by staining with hematoxylin and eosin $(\mathrm{H} \&$ E) stains $[21,26]$. Finally, cover slides mounting using few drops of clear resin (a mixture of distyrene, a plasticizer, and xylene) to the bottom before setting the cover on the tissue section slowly. Finally allowing the obtained sections to dry on a slide warmer for $24 \mathrm{~h} \mathrm{[23].}$

\section{Assessment of liver histopathology}

Liver structure evaluation after methotrexate-induced injury done by professional pathologist utilizing a light microscope and assess the grade of the induced histopathological changes using histological scoring system for NAFLD [27]. This scoring system comprehends 3 main changes in the liver: Steatosis (S) range from 0-3, Lobular inflammation (L) range from 0-3, and Ballooning of hepatocytes (B) ranges from 0-2. The total scores represent the sum of all the hepatic changes according to the following equation and ranges from 0-8 (table 1) [27]. The digital photoshop software used to simplify the range of histopathological changes by X100 magnification.

Total NAFLD Activity Score (NAS) = S + L + B [27]

\section{RESULTS}

In this experiment, the resulted histopathological findings of the treated groups were graded as mild, moderate and severe findings. These findings were examined in 4 treatment groups each contain 7 rats according to NAFLD component scoring system seen in Table 2 .

\section{Liver histopathological findings of the control group}

control group liver tissue sections show normal hepatic cellular tissue, normal lobular rearrangement with total NAS (NAFLD activity scores) of 0 as seen in (Table 2) as well as (Figs. 2, 3,4 and 5).

Liver histopathological findings of the methotrexate-treated group Liver tissue sections of this group showed moderate to severe steatosis of hepatic cells, degeneration of hepatic cell, micro- and macro-fatty vacuoles seen to join with each other forming giant fatty cysts with chronic inflammatory cells infiltration. Total NAS scores of 8 as seen in (Table 2) and in (Figs. 6, 7, 8 and 9).

Liver histopathological findings of the resatorvid pretreated group liver tissues sections' of this group show moderate hepatic cellular fatty degeneration, with a decreased number of fatty cysts chains and no inflammation observed as seen in Fig. 10, 11, 13 and 13. Total NAS scores obtained for this group of animals was 3 (Table 2).

\section{DISCUSSION}

Steatosis histopathologically characterized by the large fat vacuoles resulted from triglycerides (TG) depositionin the liver [28-30]. Their typical

Table 1: NAFLD activity score (NAS) components [27]

\begin{tabular}{|c|c|c|c|}
\hline Item & Score & Extent (\%) & Definition and comment \\
\hline \multirow[t]{4}{*}{ Steatosis } & 0 & $<5$ & Refers to the amount of surface area involved by \\
\hline & 1 & $5-33$ & steatosis as evaluated on low-to-medium power \\
\hline & 2 & $>33-66$ & examination (40X-100X); minimal steatosis $(<5 \%)$ \\
\hline & 3 & $>66$ & $\begin{array}{l}\text { receives a score of } 0 \text { to avoid giving excess weight to } \\
\text { biopsies with very little fatty change }\end{array}$ \\
\hline \multirow[t]{4}{*}{ Lobular inflammation } & 0 & No foci & Acidophil bodies are not included in this assessment nor \\
\hline & 1 & $<2$ foci/200x & is portal inflammation \\
\hline & 2 & $2-4$ foci $/ 200 x$ & \\
\hline & 3 & $>4$ foci/200x & \\
\hline \multirow[t]{3}{*}{ Hepatocyte ballooning } & 0 & None & The term "few" means rare but definite ballooned \\
\hline & 1 & Few balloon cells & hepatocytes \\
\hline & 2 & Many cells/prominent ballooning & \\
\hline
\end{tabular}

NAFLD: Non-alcoholic fatty liver disease, NAS: NAFLD activity scores 
Table 2: NAFLD activity score (NAS) components of the treatment groups

\begin{tabular}{|c|c|c|c|}
\hline \multirow[t]{2}{*}{ Score components } & \multicolumn{3}{|l|}{ Groups* } \\
\hline & Control group** & MTX group** & $\begin{array}{l}\text { Resatorvid } \\
\text { pre-treated group** }\end{array}$ \\
\hline \multicolumn{4}{|l|}{ Steatosis } \\
\hline Score & 0 & 3 & 2 \\
\hline Extent & $<5 \%$ & $>66 \%$ & $33-66 \%$ \\
\hline \multicolumn{4}{|l|}{ Lobular inflammation } \\
\hline Score & 0 & 2 & 0 \\
\hline Extent & None & $2-4$ foci $/ 200 x$ & No inflammation \\
\hline \multicolumn{4}{|c|}{ Ballooning degeneration } \\
\hline Score & 0 & 2 & 1 \\
\hline Extent & None & Many & Few cells \\
\hline Total scores & 0 & 8 & 3 \\
\hline
\end{tabular}

NAS: NAFLD activity scores, ${ }^{*} \mathrm{n}=28$ rats for the treatment groups, ${ }^{* *} \mathrm{n}=7$ rats for each group, ${ }^{* * *}$ Total score graded as severe ( $>=5$ ), moderate $(3-4)$ and mild $(<3)$.

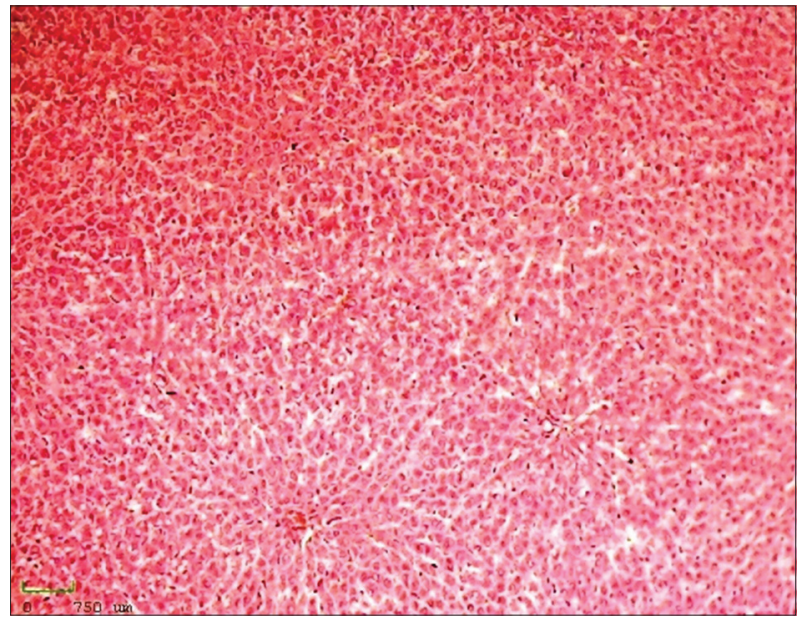

Fig. 2: Liver section of normal control rats (no abnormality), $\mathrm{H}$ and $\mathrm{E} \times 100$

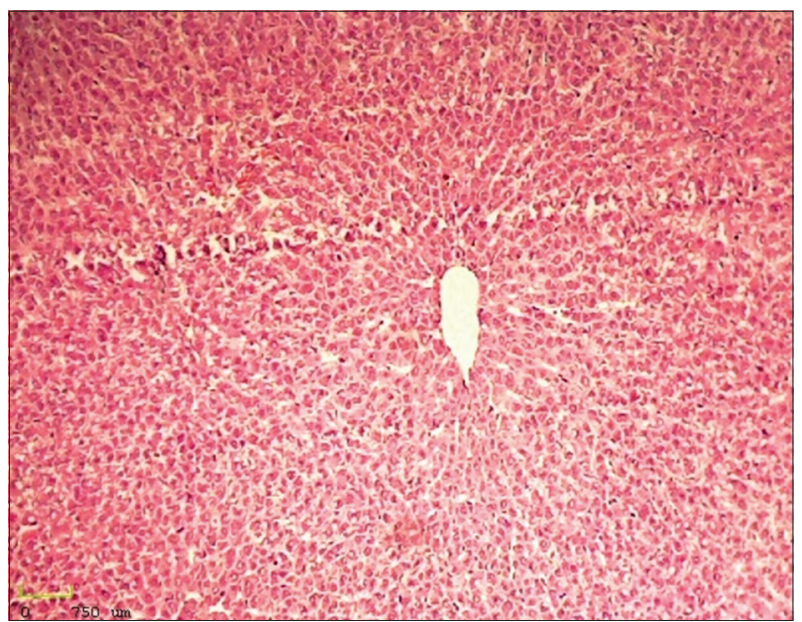

Fig. 3: Liver section of normal control rats (no abnormality), $\mathrm{H}$ and $\mathrm{E} \times 100$

presentation involves microvesicular changes: the presence of small fat vacuoles (liposomes) surrounding the nucleus at the centre of hepatocytes due to mitochondrial injury [31,32]. The macrovesicular changes: these are the sequel follows microvesicular vacuoles that represent "small and large fat droplets" which occupies the whole hepatocyte and pushes the nucleus to the edge of the cell. These droplets can re-join together resulting in the development of irreversible fatty cysts which later appears empty vacuoles due to lipolysis [28,32,33], and Finally, Steatohepatitis refers to

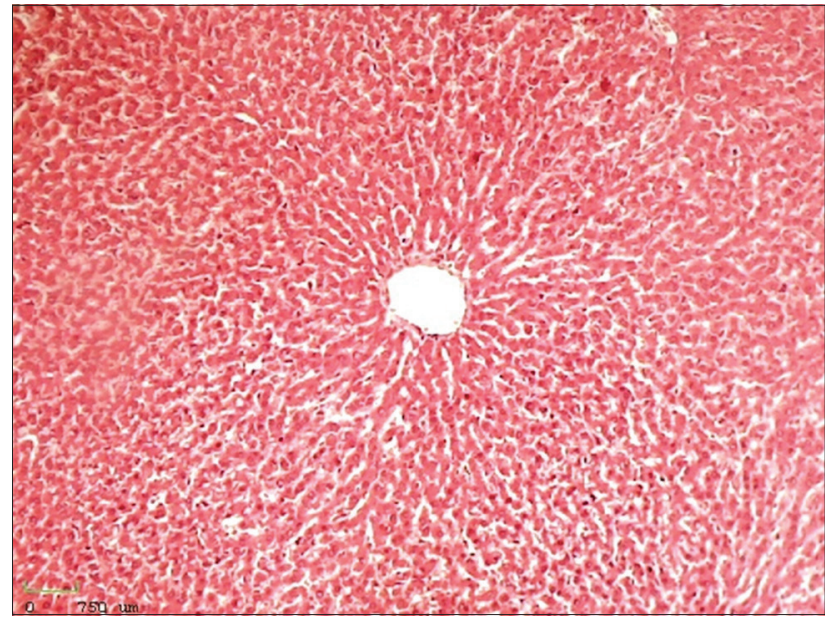

Fig. 4: Liver section of normal control rats (no abnormality), $H$ and $E \times 100$

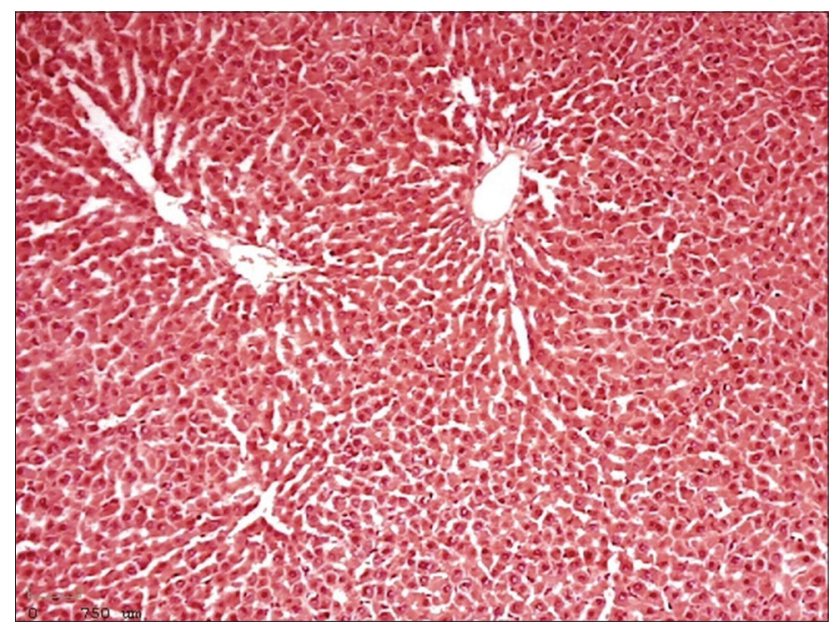

Fig. 5: Liver section of normal control rats (no abnormality), $\mathrm{H}$ and $\mathrm{E} \times \mathbf{1 0 0}$

steatosis coexisting with hepatocellular ballooning, fibrosis, and lobular inflammation. It is also attributed to oxidative stress and mitochondrial loss of function $[10,31,32]$.

Chemotherapeutic drugs are the usual cause of multiple organ damage [34], especially those with self-renewing tissues. Since the liver is the main site for drug metabolism, so it is highly vulnerable to drug-induced liver injuries $[11,28,31]$. MTX is a classical chemotherapeutic and immunosuppressive 


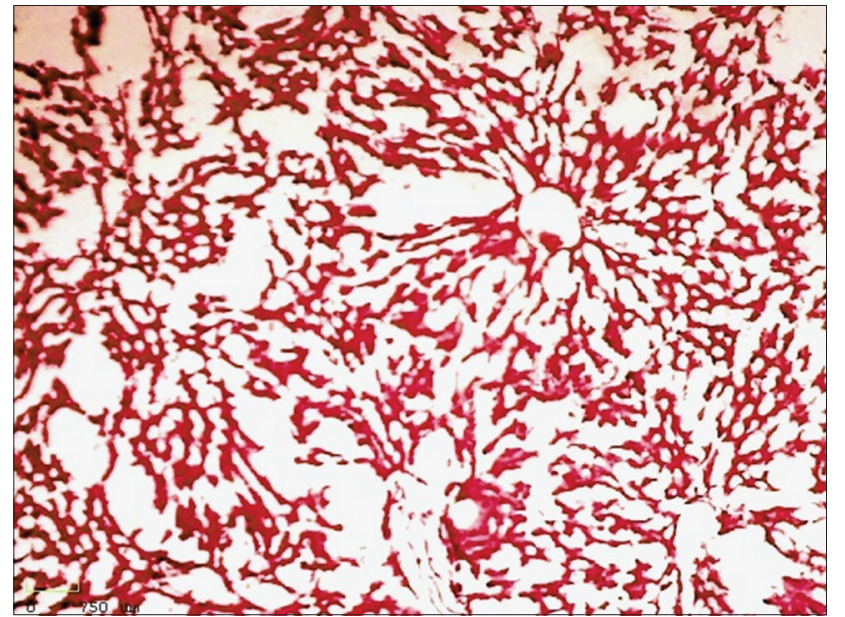

Fig. 6: Liver section of methotrexate-treated rats (moderate-tosevere steatosis) showing fatty degeneration of hepatic cells, microvesicular and macrovesicular fat vacuoles are shown joining each other and forming fatty cystic chains, $\mathrm{H}$ and $\mathrm{E} \times 100$

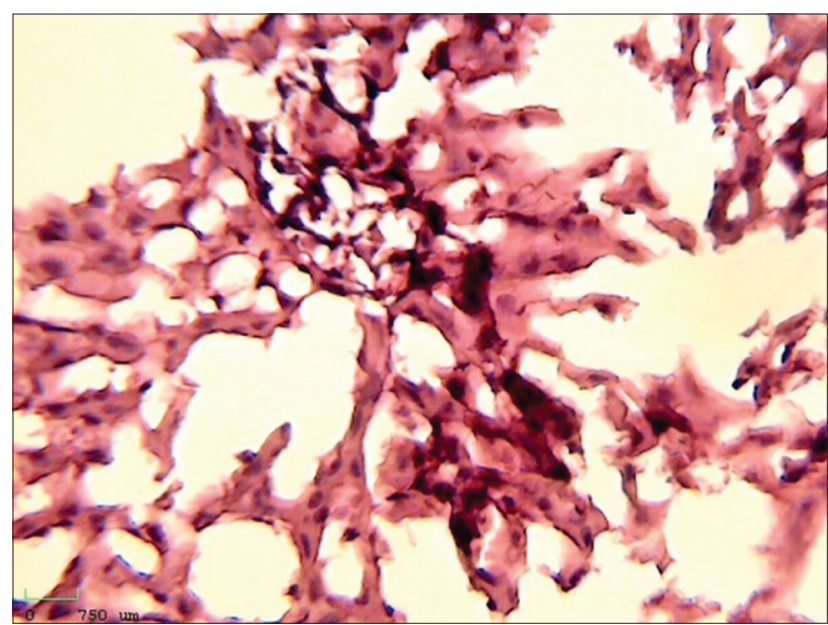

Fig. 7: Liver section of methotrexate-treated rats (moderate to severe steatosis) showing fatty degeneration of hepatic cells, micro-vesicular and macro-vesicular fat vacuoles are shown joining each other and forming fatty cystic chains, $\mathrm{H}$ and $\mathrm{E} \times 100$

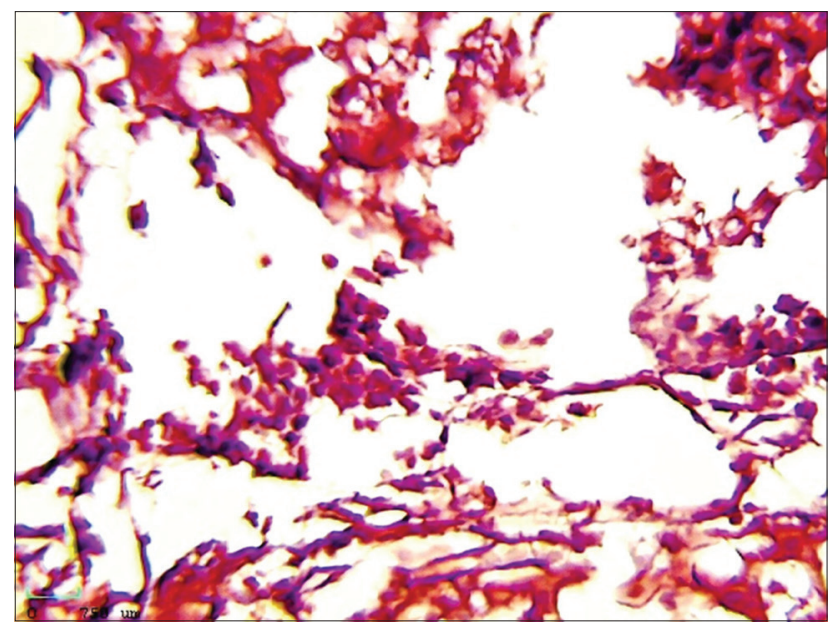

Fig. 8: Liver section of methotrexate-treated rats (moderate to severe steatosis) showing fatty cyst chains with chronic inflammatory cells infiltration, $\mathrm{H}$ and $\mathrm{E} \times 100$

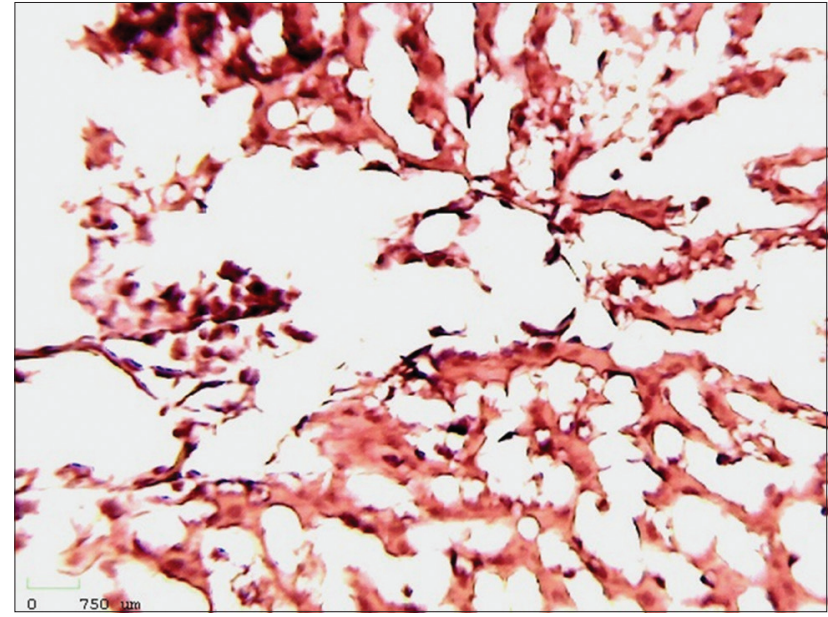

Fig. 9: Liver section of methotrexate-treated rats (moderate to severe steatosis) showing fatty cyst chains with chronic inflammatory cells infiltration, $\mathrm{H}$ and $\mathrm{E} \times \mathbf{1 0 0}$

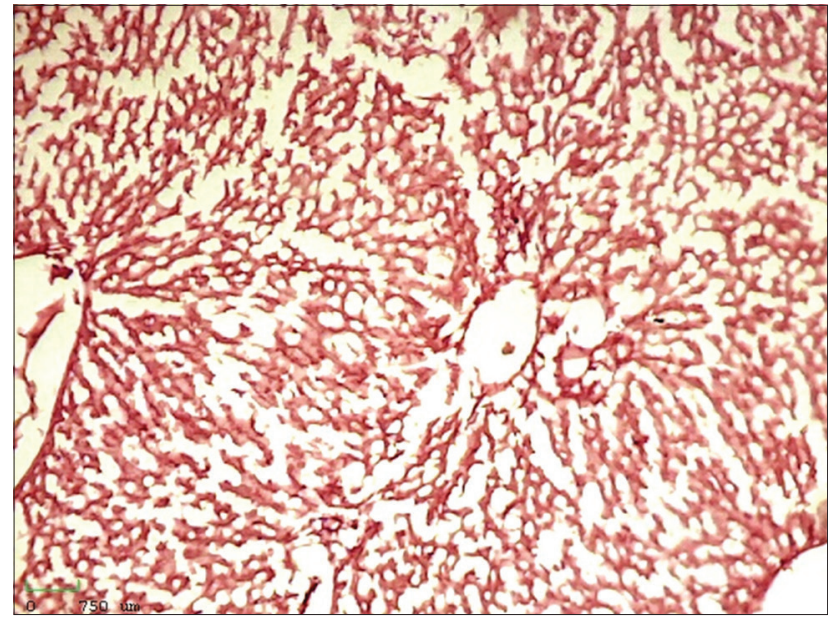

Fig. 10: Liver section of resatorvid pre-treated rats showing moderate steatosis with macrovesicular and microvesicular hepatic cell fatty degeneration and fewer numbers of fatty cysts chains, $\mathrm{H}$ and $\mathrm{E} \times \mathbf{1 0 0}$

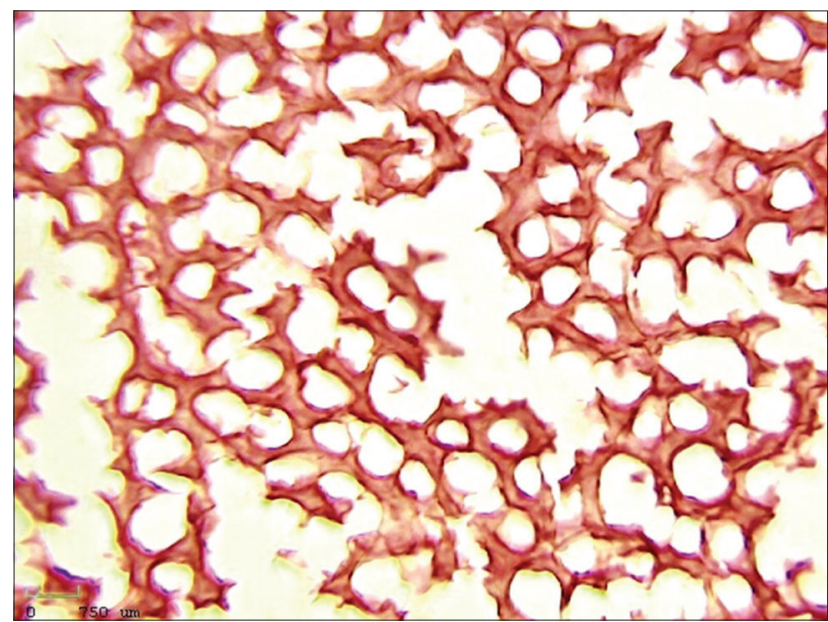

Fig. 11: Liver section of resatorvid pre-treated rats showing moderate steatosis with hepatic cell fatty degeneration and fewer number of fatty cysts chains. No inflammation observed $H$ and $E$ $\times 100$ 


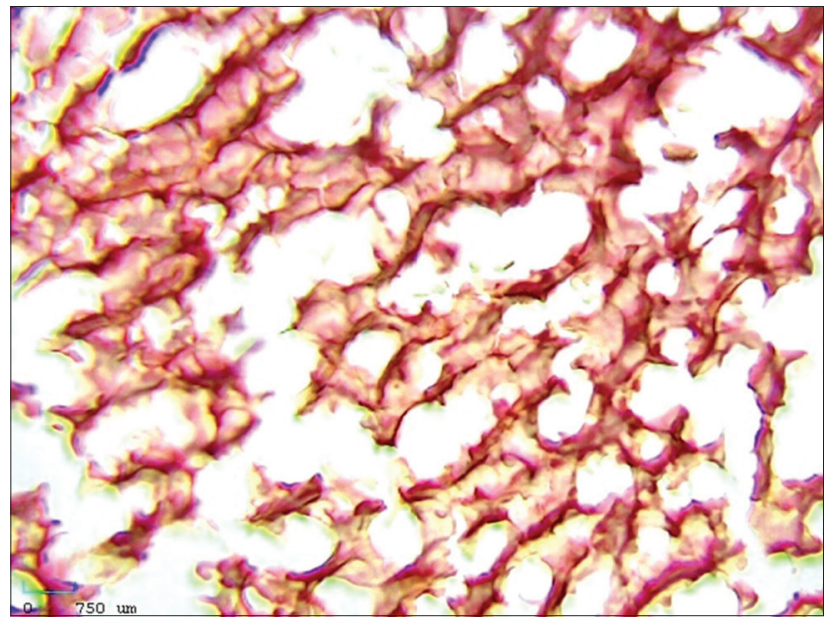

Fig. 12: Liver section of resatorvid pretreated rats showing moderate steatosis with macrovesicular hepatic cells fatty degeneration and fewer number of fatty cysts chains. No inflammation observed $H$ and $E \times 100$

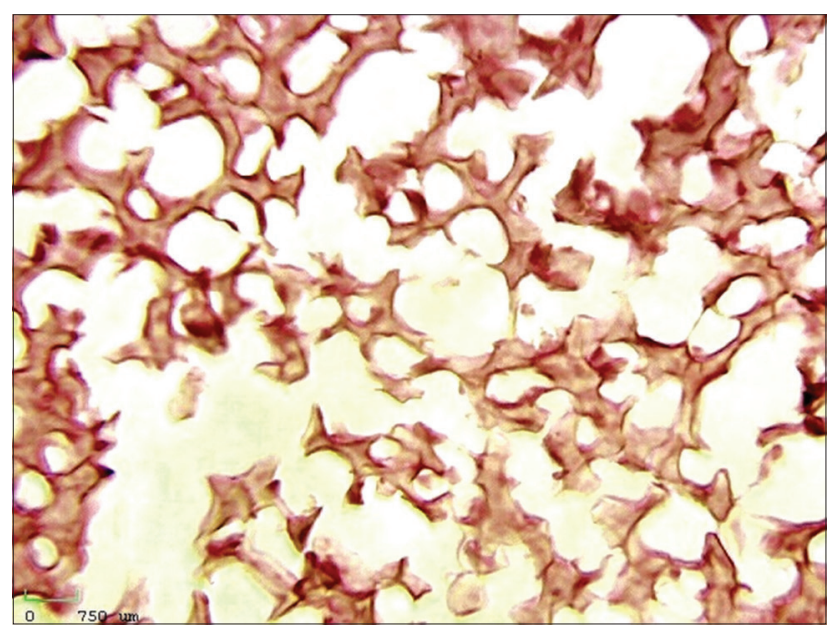

Fig. 13: Liver section of resatorvid pretreated rats showing moderate steatosis with hepatic cell fatty degeneration and fatty cysts chains. No inflammation observed $H$ and $E \times 100$

drug [35]. It resulted in haematological and gastrointestinal toxicities even when administered in low-dose regimen [36,37], and it is a usual cause of hepatocellular injury and death [38,39]. A methotrexate-induced liver injury may present as steatosis, cholestasis, fibrosis, cirrhosis, and in rare case acute liver failure $[11,31,34,40]$. In this study, we found that MTXtreated animals showed moderate to severe steatosis in comparison with animals in the control group. Both microvesicular and macrovesicular fatty vacuoles that are rejoining and form a fatty cyst (ballooning degeneration), pyknosis of chromatin in the nucleus was seen with a peripheralized nuclei that result in a shape of a signet ring. Moderate inflammation observed in the histological section of treated animals with infiltration of chronic inflammatory cells. The histopathological changes we achieved in this study are in consistent with the previous studies, which described severe focal necrosis accompanied by hepatic granular damage, abnormal hepatocytes rearrangement around central vein with shrunken and inflected nuclei, infiltration of mononuclear cells, vascular congestion, increased KCs activation and proliferated connective tissue in hepatic sections of those rats treated with MTX [15,20,21,34,41-43]. Despite, our finding represent the moderate-severe patterns of MTX-induced liver injury and thus we described milder steatohepatitic changes [11,31,34,39,40].

These changes attributed to MTX increment in both oxidative and nitrosative stress, that resulted from liver exposure to high levels of MTX-oxidizing metabolites [11,31]. Methotrexate inhibition of cytoplasmic de novo synthetic pathways of purines, pyrimidines as well as polyamines that leads to diminished hepatic folate reservoir, restrain folate entrance to the mitochondria, affect nucleic acid synthesis in S-phase and thus render hepatic cell death and further generation of FR $[9,23,44]$. Imbalance in cellular oxidant/antioxidant enzymes, which causes decreased availability of cytosolic nicotinamide adenosine diphosphate hydrogen (NADPH) that in turn affect the reduced state of cellular glutathione, also the decreased the level of superoxide dismutase and catalase $[20,21,39,42]$. These mechanisms will obstruct hepatic cholesterol and TG metabolism resulting in fatty infiltration, also would increase cellular sensitization to FR leading to stimulation of inflammatory response by activating KCs, HSCs, and macrophages (MQ). Such scenarios lead to fibrosis, leukocyte accumulation, neutrophils secretion of pro-inflammatory enzymes and CKs like inducible nitric oxide synthase (iNOS), Nuclear factor- $\kappa \mathrm{B}(\mathrm{NF}-\kappa \mathrm{B})$ and tumour necrosis factor- $\alpha$ (TNF- $\alpha$ ). This, in turn, causes more production of FR causes sinusoidal congestion, dilation, hepatic fatty vacuolation, focal necrosis and portal inflammation which is the typical pattern of druginduced steatohepatitis (DISH) produced by FR $[20,31,34,40]$.

Liver sections of resatorvid pre-treated rats showed moderate steatosis with NAFLD scores of 3 , some restoration of macrovesicular and microvesicular hepatocytes fatty degeneration, and decrease in number of fatty cysts chains, with total reservation of infiltrated inflammatory cells but with incomplete ameliorating of the hepatic histological injuries induced by MTX. This protective effect is promising but not satisfying. It may indicate the requirement of longer treatment courses or coadministration courses. Still, it could be explained by resatorvid antagonism of TLR4 activation and upregulation caused by intracellular and extracellular damage-associated molecular patterns released during oxidative stress [45]. As a selective antagonist of TLR4, resatorvid inhibits both TLR4-Myeloid differential88 (MyD88)-dependent and MyD88-independent signaling pathways which induce inflammatory immune response and release of CK as TNF- $\alpha$ and interleukin-6 [46-48]. This inhibition is rather attributed to the inhibition of FR generation resultant from the activation of TLR4-MyD88-dependent signaling cascade that stimulates mitogen-activated protein kinase and c-Jun phosphorylation which are involved in FR generation [47,49].

\section{CONCLUSION}

Resatorvid hepatoprotective effect against MTX-induced injury was promising throughout resolving the accompanied inflammation and partial restoring histopathological fatty alterations.

\section{ACKNOWLEDGMENT}

Thanks to the Iraqi Centre for Cancer and Medical Genetic research as well as to the department of pharmacology at the College of Medicine, Mustansiriyah University for providing the essential facilities to develop this research.

\section{AUTHORS' CONTRIBUTION}

Bassim S. Ahmed- contributed to the definition of intellectual content, experimental study, data analysis, manuscript revision as well as being guarantor, also contributed in the financial support. Alaa F. Hassan - contributed to the design, experimental study, data analysis and acquisition, manuscript preparation and review, and guarantor and also contributed in the financial support. Samer F. Hassan - contributed in the financial support, manuscript revision, and editing.

\section{CONFLICTS OF INTEREST}

the authors have no conflicts of interest.

\section{REFERENCES}

1. Zhang Y, Peng W, Ao X, Dai H, Yuan L, Huang X, et al. TAK-242, a toll-like receptor 4 antagonist, protects against aldosterone-induced cardiac and renal injury. PLoS One 2015;10:e0142456.

2. Gárate I, García-Bueno B, Madrigal JL, Caso JR, Alou L, Gómez-Lus ML, 
et al. Toll-like 4 receptor inhibitor TAK-242 decreases neuroinflammation in rat brain frontal cortex after stress. J Neuroinflammation 2014;11:8.

3. Hussey SE, Liang H, Costford SR, Klip A, DeFronzo RA, SanchezAvila A, et al. TAK-242, a small-molecule inhibitor of toll-like receptor 4 signalling, unveils similarities and differences in lipopolysaccharideand lipid-induced inflammation and insulin resistance in muscle cells. Biosci Rep 2012;33:37-47.

4. Takashima K, Matsunaga N, Yoshimatsu M, Hazeki K, Kaisho T, Uekata M, et al. Analysis of binding site for the novel small-molecule TLR4 signal transduction inhibitor TAK-242 and its therapeutic effect on mouse sepsis model. Br J Pharmacol 2009;157:1250-62.

5. Matsunaga N, Tsuchimori N, Matsumoto T, Ii M. TAK-242 (resatorvid), a small-molecule inhibitor of toll-like receptor (TLR) 4 signaling, binds selectively to TLR4 and interferes with interactions between TLR4 and its adaptor molecules. Mol Pharmacol 2011;79:34-41.

6. Kiziltas S. Toll-like receptors in pathophysiology of liver diseases. World J Hepatol 2016;8:1354-69.

7. Guo J, Friedman SL. Toll-like receptor 4 signaling in liver injury and hepatic fibrogenesis. Fibrogenesis Tissue Repair 2010;3:21.

8. Broering R, Lu M, Schlaak JF. Role of toll-like receptors in liver health and disease. Clin Sci (Lond) 2011;121:415-26.

9. Mahmoud AM, Hussein OE, Hozayen WG, Abd El-Twab SM. Methotrexate hepatotoxicity is associated with oxidative stress, and down-regulation of PPAR $\gamma$ and nrf2: Protective effect of 18 $\beta$-glycyrrhetinic acid. Chem Biol Interact 2017;270:59-72.

10. Pandit A, Sachdeva T, Bafna P. Drug-induced hepatotoxicity: A review. J Appl Pharm Sci 2012;2:233-4.

11. Khafaga AF, El-Sayed YS. Spirulina ameliorates methotrexate hepatotoxicity via antioxidant, immune stimulation, and proinflammatory cytokines and apoptotic proteins modulation. Life Sci 2018;196:9-17.

12. Pierce RH, Campbell JS, Stephenson AB, Franklin CC, Chaisson M, Poot $\mathrm{M}$, et al. Disruption of redox homeostasis in tumor necrosis factor-induced apoptosis in a murine hepatocyte cell line. Am J Pathol 2000;157:221-36

13. Hadi N, Jabber H. Potential activity of GIT27 against renal ischemia reperfusion injury: An experimental study in male rats. Pathophysiol Cell Inj J 2016;5:87-99.

14. Olayinka ET, Ore A, Adeyemo OA, Ola OS. Ameliorative effect of gallic acid on methotrexate-induced hepatotoxicity in rat. J Xenobiotics 2016;6:6092.

15. Yucel Y, Oguz E, Kocarslan S, Tatli F, Gozeneli O, Seker A, et al. The effects of lycopene on methotrexate-induced liver injury in rats. Bratisl Lek Listy 2017;118:212-6.

16. Zhao Y, Xin Y, Gao J, Teng RY, Chu HC. Analgesic effect of TAK-242 on neuropathic pain in rats. Int J Clin Exp Med 2015;8:11202-7.

17. Yousif NG, Mohammad BI, Al-Khalidy SA. Effect of N-acetyl cysteine and TAK-242 on sepsis induced myocardial injury: Down regulation of MMP-2 pathway in mice. Pathophysiol Cell Inj J 2016;5:111-25.

18. Hawk CT, Leary ST, Morris TH. Formulary for Laboratory Animals. $3^{\text {rd }}$ ed. IA, USA: Blackwell Publishing; 2005.

19. Institutional Animal Care and Use Committee (IACUC). IACUC Guidelines: Anesthesia. USA: University of IOWA; 2017.

20. Demiryilmaz I, Sener E, Cetin N, Altuner D, Suleyman B, Albayrak F, et al. Biochemically and histopathologically comparative review of thiamine's and thiamine pyrophosphate's oxidative stress effects generated with methotrexate in rat liver. Med Sci Monit 2012;18:BR475-81

21. Dalaklioglu S, Genc GE, Aksoy NH, Akcit F, Gumuslu S. Resveratrol ameliorates methotrexate-induced hepatotoxicity in rats via inhibition of lipid peroxidation. Hum Exp Toxicol 2013;32:662-71.

22. Suvarna SK, Layton C, Bancroft JD. Bancroft's Theory and Practice of Histological Techniques. $7^{\text {th }}$ ed. Oxford: Churchill Livingstone Elsevier; 2013

23. Armagan I, Bayram D, Candan IA, Yigit A, Celik E, Armagan HH, et al. Effects of pentoxifylline and alpha lipoic acid on methotrexateinduced damage in liver and kidney of rats. Environ Toxicol Pharmacol 2015;39:1122-31.

24. Akbulut S, Elbe H, Eris C, Dogan Z, Toprak G, Otan E, et al. Cytoprotective effects of amifostine, ascorbic acid and N-acetylcysteine against methotrexate-induced hepatotoxicity in rats. World J Gastroenterol 2014;20:10158-65.

25. Tunali-Akbay T, Sehirli O, Ercan F, Sener G. Resveratrol protects against methotrexate-induced hepatic injury in rats. J Pharm Pharm Sci
2010;13:303-10.

26. Oya S, Yokoyama Y, Kokuryo T, Uno M, Yamauchi K, Nagino M, et al. Inhibition of toll-like receptor 4 suppresses liver injury induced by biliary obstruction and subsequent intraportal lipopolysaccharide injection. Am J Physiol Gastrointest Liver Physiol 2014;306:G244-52.

27. Kleiner DE, Brunt EM, Van Natta M, Behling C, Contos MJ, Cummings OW, et al. Design and validation of a histological scoring system for nonalcoholic fatty liver disease. Hepatology 2005;41:1313-21.

28. Singh R, Kumar S, Rana AC, Sharma N. Different models of hepatotoxicity and related liver disease: A review. Int Res J Pharm 2012;3:86-95

29. Cao L, Quan XB, Zeng WJ, Yang XO, Wang MJ. Mechanism of hepatocyte apoptosis. J Cell Death 2016;9:19-29.

30. Fagone P, Mangano K, Mammana S, Pesce A, Pesce A, Caltabiano R, et al. Identification of novel targets for the diagnosis and treatment of liver fibrosis. Int J Mol Med 2015;36:747-52.

31. Miele L, Liguori A, Marrone G, Biolato M, Araneo C, Vaccaro FG, et al. Fatty liver and drugs: The two sides of the same coin. Eur Rev Med Pharmacol Sci 2017;21:86-94

32. Ramachandran R, Kakar S. Histological patterns in drug-induced liver disease. J Clin Pathol 2009;62:481-92.

33. Kleiner DE. The histopathological evaluation of drug-induced liver injury. Histopathology 2017;70:81-93.

34. Uraz S, Tahan V, Aygun C, Eren F, Unluguzel G, Yuksel M, et al. Role of ursodeoxycholic acid in prevention of methotrexate-induced liver toxicity. Dig Dis Sci 2008;53:1071-7.

35. Coskun M, Steenholdt C, de Boer NK, Nielsen OH. Pharmacology and optimization of thiopurines and methotrexate in inflammatory bowel disease. Clin Pharmacokinet 2016;55:257-74.

36. Gaies E, Jebali N, Trabelsi S, Salouage I, Charfi R, Lakhal M, et al. Methotrexate side effects review. J Drug Metab Toxicol 2012;3:125.

37. Dey P, Saha MR, Sen A. An overview on drug-induced hepatotoxicity. Asian J Pharm Clin Res 2013;6:1-4.

38. Anila R, Sathiya S, Babu CS, Rajkumar J. In vitro and in vivo protective effects of ambrex, a polyherbal formulation against methotrexate induced damages in hepatic cells. Int J Pharm Pharm Sci 2015;7:164-70.

39. David AV, Satyanarayana N, Parasuraman S, Bharathi S, Arulmoli R. Ameliorative effect of quercetin on methotrexate induced toxicity in Sprague-Dawley rats: A histopathological study. Indian J Pharm Educ Res 2016;50 S 3:S200-8.

40. Cure E, Kirbas A, Tumkaya L, Cure MC, Kalkan Y, Yilmaz A, et al. Protective effect of infliximab on methotrexate-induced liver injury in rats: Unexpected drug interaction. J Cancer Res Ther 2015;11:164-9.

41. Vardi N, Parlakpinar H, Cetin A, Erdogan A, Cetin Ozturk I. Protective effect of beta-carotene on methotrexate-induced oxidative liver damage. Toxicol Pathol 2010;38:592-7.

42. Daniel JA, Das S, Jayan N, Devi SA. Protective activity of Asparagus racemosus in methotrexate-induced liver toxicity in wistar rats. Asian $\mathrm{J}$ Pharm Clin Res 2018;11:253-6.

43. Khokhar A, Qayyum A, Khan MW. Protective effect of melatonin against methotrexate induced hepatotoxicity in mice. Pak Armed Forces Med J 2017;67:126-30.

44. Abo-Haded HM, Elkablawy MA, Al-Johani Z, Al-Ahmadi O, ElAgamy DS. Hepatoprotective effect of sitagliptin against methotrexate induced liver toxicity. PLoS One 2017;12:e0174295.

45. Salama M, Elgamal M, Abdelaziz A, Ellithy M, Magdy D, Ali L, et al. Toll-like receptor 4 blocker as potential therapy for acetaminopheninduced organ failure in mice. Exp Ther Med 2015;10:241-6.

46. Wen Z, Ji X, Tang J, Lin G, Xiao L, Liang C, et al. Positive feedback regulation between transglutaminase 2 and toll-like receptor 4 signaling in hepatic stellate cells correlates with liver fibrosis post Schistosoma japonicum infection. Front Immunol 2017;8:1808.

47. Khan M, Farahvash A, Douda D, Licht JC, Grasemann H, Sweezey N, et al. JNK activation turns on LPS-and gram-negative bacteria-induced NADPHt oxidase-dependent suicidal NETosis. Sci Rep 2017;7:3409.

48. Yu P, Cheng X, Du Y, Huang L, Dong R. TAK-242 can be the potential agent for preventing invasion and metastasis of hepatocellular carcinoma. Med Hypotheses 2013;81:653-5.

49. Lin A, Wang G, Zhao H, Zhang Y, Han Q, Zhang C, et al. TLR4 signaling promotes a $\mathrm{COX}-2 / \mathrm{PGE}_{2} / \mathrm{STAT} 3$ positive feedback loop in hepatocellular carcinoma (HCC) cells. Oncoimmunology 2016;5:e1074376. 